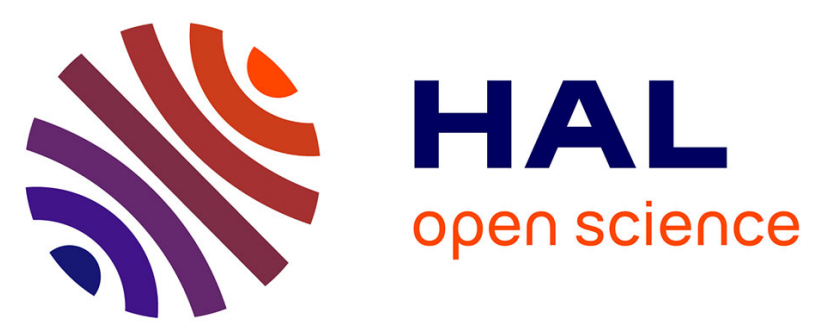

\title{
Glyburide therapy for gestational diabetes: Glycaemic control, maternal hypoglycaemia, and treatment failure
}

Hélène Affres, Marie Victoire Senat, Alexandra Letourneau, Philippe Deruelle, Magali Coustols-Valat, Hanane Bouchghoul, Jean Bouyer

\section{- To cite this version:}

Hélène Affres, Marie Victoire Senat, Alexandra Letourneau, Philippe Deruelle, Magali Coustols-Valat, et al.. Glyburide therapy for gestational diabetes: Glycaemic control, maternal hypoglycaemia, and treatment failure. Diabetes \& Metabolism, 2021, 47 (4), 10.1016/j.diabet.2020.11.002 . hal-03329903

\section{HAL Id: hal-03329903 \\ https://hal.science/hal-03329903}

Submitted on 5 Nov 2021

HAL is a multi-disciplinary open access archive for the deposit and dissemination of scientific research documents, whether they are published or not. The documents may come from teaching and research institutions in France or abroad, or from public or private research centers.
L'archive ouverte pluridisciplinaire HAL, est destinée au dépôt et à la diffusion de documents scientifiques de niveau recherche, publiés ou non, émanant des établissements d'enseignement et de recherche français ou étrangers, des laboratoires publics ou privés. 
Glyburide therapy for gestational diabetes: glycemic control, maternal hypoglycemia, and treatment failure

Hélène AFFRES, MD ${ }^{1}$, Marie-Victoire SENAT, MD, $\mathrm{PhD}^{2,3}$, Alexandra LETOURNEAU, MD4, Philippe DERUELLE, MD, PhD ${ }^{5,6}$, Magali COUSTOLS-VALAT, $\mathrm{MD}^{7}$, Hanane BOUCHGHOUL, MD ${ }^{2,3}$, Jean BOUYER, $\mathrm{PhD}^{3}$

${ }^{1}$ Assistance Publique-Hôpitaux de Paris, Department of Reproductive Endocrinology, Bicêtre Hospital, Le Kremlin-Bicêtre, France

${ }^{2}$ Assistance Publique-Hôpitaux de Paris, Department of Gynecology-Obstetrics, Bicêtre Hospital, Le Kremlin-Bicêtre, France

${ }^{3}$ Université Paris-Saclay, UVSQ, Inserm, CESP, 94807, Villejuif, France

${ }^{4}$ Assistance Publique-Hôpitaux de Paris, Department of Gynecology-Obstetrics, Antoine Beclere Hospital, Clamart, France

${ }^{5}$ EA 4489, Environnement périnatal et croissance, PRES Université Lille Nord de France, 59000, Lille, France

${ }^{6}$ Department of Obstetrics, Strasbourg University Hospital, University of Strasbourg, Strasbourg, France

${ }^{7}$ Department of Endocrinology-Obstetric, Toulouse University Hospital, Toulouse, France

Email and ORCID identifiers

Hélène AFFRES
Marie-Victoire SENAT
Alexandra LETOURNEAU
Philippe DERUELLE
Magali COUSTOLS-VALAT
Hanane BOUCHGHOUL
Jean BOUYER

Corresponding author

Jean Bouyer

CESP-Inserm U1018

82, rue du Général Leclerc

94276 Le Kremlin-Bicêtre Cedex

Telephone number: +33145212035

Email: jean.bouyer@inserm.fr

Word count:

Main text: 2740

Abstract: 239
helene.affres@aphp.fr marie-victoire.senat@aphp.fr letourneau.alexandra@aphp.fr philippe.deruelle@chru-strasbourg.fr magali.coustols@wanadoo.fr hanane.bouchghoul@aphp.fr jean.bouyer@inserm.fr
$\underline{0000-0002-2329-6575}$
0000-0003-4273-6553 0000-0003-2135-7853 0000-0002-8482-2815 0000-0003-4861-0783 


\section{Abstract}

\section{Aims}

The recommended first-line treatment for women with gestational diabetes mellitus (GDM) in the case of failure of diet is insulin. Recent results suggest that there is a potential role for glyburide therapy and highlight the need for better knowledge of glycemic control with glyburide. The objective of this study was to describe and quantify in women with GDM the quality of glycemic control, including the risk of maternal hypoglycemia and of therapy failure.

\section{Methods}

This is a secondary analysis of the French INDAO non-inferiority trial from 2012 to 2016, in which 890 women with GDM randomized to receive glyburide or insulin treatment were compared for perinatal outcomes. Blood glucose concentrations were assessed prospectively during pregnancy. Optimal glycemic control was defined as less than $20 \%$ of blood glucose values exceeding the targets.

\section{Results}

More than $50 \%$ of the women had optimal glycemic control with glyburide, similar to that with insulin. Around $40 \%$ of the women had at least one episode of hypoglycemia, more than with insulin. However, those hypoglycemic episodes were mostly moderate and the rate of severe hypoglycemia decreased significantly during the course of the trial.

Failure of glyburide treatment (switch to insulin therapy) occurred in $18 \%$ of women and had few predictors. However, when failure occurred, glycemic control was improved after switching to insulin.

\section{Conclusions}

Glyburide is an effective treatment for reaching glycemic goals during pregnancy in women with GDM. The risk of maternal hypoglycemia may be minimized by clinical 
Diabetes \& Metabolism - accepted version

practice experience. These findings could be taken into account in the management of GDM.

Key words: gestation diabetes mellitus; glyburide; hypoglycemia; blood glucose control 


\section{Introduction}

The rate of gestational diabetes mellitus (GDM) ranges from $9 \%$ to $25 \%$, depending on the characteristics of the mother, and has been increasing over time, because of the rising prevalence of obesity and increasing maternal age [1, 2]. Two large randomized controlled studies $[3,4]$ have shown that treatment of women with mild GDM in order to reach strict glycemic goals can reduce the frequency of some adverse perinatal outcomes, especially macrosomia. Therefore, the aim of treatment of GDM is to normalize maternal fasting and postprandial glucose levels in order to limit perinatal complications. The recommended first-line treatment for women with GDM in the case of failure of diet is insulin [5]. However, oral agents may have advantages over insulin due to their lower cost, easier administration, easier storage, and better acceptance, and may be required in some situations.

Since the first randomized trial by Langer et al [6], meta-analyses based on randomized trials have shown that maternal glycemic control is similar with insulin and glyburide [7-12]. Recently, the INDAO randomized non-inferiority trial (NCT01731431) [13] compared glyburide to insulin whose primary outcome was a composite criterion of perinatal complications associated with GDM, including macrosomia, neonatal hypoglycemia, and hyperbilirubinemia,. Although it did not show the non-inferiority of glyburide, this trial showed that the increase in neonatal complications was no more than $10.5 \%$ and concerned mainly neonatal transient hypoglycemia. This leaves a potential role for glyburide therapy and highlights the need for better knowledge of glycemic control with glyburide and of which patients could benefit from it without failure. The INDAO trial offers this opportunity since it gathered a large sample of women who had been followed up until the end of pregnancy. 
The objectives of this ancillary analysis of INDAO data were to describe and quantify in women with GDM the quality of glycemic control and the risk of maternal hypoglycemia with glyburide compared to insulin, and to study glyburide therapy failure in women who switched to insulin.

The INDAO trial protocol, including ancillary studies like the present one, was approved by the ethics committee of the Poissy St-Germain Hospital, France (2011004221-28) and registered in clinicaltrials.gov (NCT01731431). 


\section{Material and methods}

This study is an ancillary analysis of the INDAO non-inferiority trial conducted from May 2012 to November 2016 in 13 tertiary care university hospitals in France, comparing glyburide versus insulin for the prevention of perinatal complications of GDM. Detailed information regarding the design of the trial has been reported elsewhere [13]. In summary, women with a singleton pregnancy and diagnosed with GDM with the $75 \mathrm{~g}$ oral glucose tolerance test using International Association of the Diabetes and Pregnancy Study Groups (IADPSG) criteria [14] between 24 and 34 weeks of gestation were given individual nutrition education by a dietitian and were taught to self-monitor capillary blood glucose four times daily (fasting and 2 hours after each meal). Goals were considered not achieved after 10 days of well-managed diet if at least 2 blood glucose values above the targets were observed over a week: fasting $\geq 0.95 \mathrm{~g} / \mathrm{L} ; 2$-hour postprandial $\geq 1.20 \mathrm{~g} / \mathrm{L}$, with no variations in the diet. In that case, the woman was eligible for randomization between the two therapeutic strategies: insulin or glyburide.

\section{Treatments}

Insulin: The starting dose for rapid analogs was 4 IU subcutaneously before meals, one to three times daily, and this was increased by 2 IU every 2 days according to the postprandial blood glucose value. When necessary, the starting dose for basal or intermediate insulin was 4 to 8 IU subcutaneously at bedtime, and increased by 2 IU every two days according to the morning fasting blood glucose value. Women were taught to self-adjust their insulin doses in order to reach and maintain glycemic goals throughout pregnancy.

Glyburide: The starting dose for therapy was $2.5 \mathrm{mg}$ orally once a day before breakfast and could be increased if necessary 4 days later by $2.5 \mathrm{mg}$ and thereafter by $5 \mathrm{mg}$ every four days in two doses morning and evening before meals up to a 
maximum of $20 \mathrm{mg}$ per day. In cases of symptomatic hypoglycemia or blood glucose $<60 \mathrm{mg} / \mathrm{dL}$, glyburide dose could be decreased or returned to the previous dose. If the maximum tolerated dose was reached without achieving the desired glucose values of less than $95 \mathrm{mg} / \mathrm{dL}$ for fasting and $120 \mathrm{mg} / \mathrm{dL}$ for 2 hours postprandial, women were switched to insulin. We have considered here that all switches were glyburide therapy failures.

\section{Monitoring of glycemic control}

At each visit, all the woman's blood glucose measurements and treatment intakes since the previous visit were recorded. Glycemic control was quantified by the clinician by the percentage of her blood glucose values since the previous visit greater than $95 \mathrm{mg} / \mathrm{dL}$ for fasting and $120 \mathrm{mg} / \mathrm{dL}$ for 2 hours postprandial, which are the targets currently recommended $[3-5,15]$. Overall glycemic control per woman during treatment was quantified by computing the percentage of blood glucose values exceeding targets in all her blood glucose assays, from randomization to delivery. Two categories of glycemic control were defined (and estimated separately for fasting and postprandial blood glucose): "optimal glycemic control" ( $\leq 20 \%$ of blood glucose values exceeding targets) and "sub-optimal glycemic control" (percentage $>20 \%$ ).

Maternal hypoglycemia was defined as blood glucose below $60 \mathrm{mg} / \mathrm{dL}$, and severe hypoglycemia as blood glucose below $40 \mathrm{mg} / \mathrm{dL}$ and/or clinical symptoms of severity: confusion, poor coordination, double vision, convulsion, or inability to self-treat symptoms.

\section{Statistical analysis}

To study glycemic control and maternal hypoglycemia, women randomized to the insulin group were compared to women randomized to the glyburide group. In the 
glyburide group, women who were switched to insulin (glyburide treatment failure) were compared to women who remained in the glyburide group.

Comparisons of continuous variables were done with Student's t-test and comparisons of categorical variables were done with chi-square tests. The evolution of glycemic control during pregnancy was studied by modeling the relationship between fasting or postprandial blood glucose results and time elapsed since the start of treatment. Modeling was performed with fractional polynomials [16] with generalized linear models [17] to take into account the successive blood glucose assays for a woman during pregnancy. The rate of hypoglycemia during the course of the trial was modeled by fractional polynomials and logistic regression. Statistical analyses were performed using Stata software, release 15 [18].

This study was funded by a research grant from the French Ministry of Health and was sponsored by Paris Public Hospitals (AP-HP, Assistance Publique des Hôpitaux de Paris), via its Clinical Research Department. The funders had no role in study design, data collection and analysis, decision to publish, or preparation of the manuscript.

\section{Results}

\section{Characteristics of the women}

From May 2012 through September 2016, 914 women with GDM were randomized: 460 to the glyburide group and 454 to the insulin group. After randomization, 18 (2.0\%) patients were excluded because they did not meet the inclusion criteria and six had no primary outcome or refused the treatment. The 890 remaining women were of mean age 32.7 years, had a mean pre-pregnancy body mass index (BMI) of $27.6 \mathrm{~kg} / \mathrm{m}^{2}, 63.5 \%$ were multiparous and $20.3 \%$ had had previous GDM. Among the 448 women randomized to the glyburide group, 81 (18\%) were switched to insulin. 
Data on glycemic control during pregnancy were available for 845 women (95\%): 418 in the insulin group and 427 in the glyburide group. We verified that the loss of $5 \%$ of women did not alter the balance between the 2 groups.

Glycemic control and hypoglycemia during treatment

On average, with glyburide, $80 \%$ of the fasting blood glucose measurements and $78 \%$ of the postprandial blood glucose measurements of a woman were within the targets. More than $60 \%$ of the women with glyburide had optimal fasting glycemic control and almost 50\% optimal postprandial glycemic control. Glycemic control (fasting or postprandial) was similar with glyburide and insulin (Table 1). Glycemic control during pregnancy improved with both treatments to the same extent according to the time elapsed since the start of the treatment (Figure 1).

Among women treated with glyburide, $41.1 \%$ had at least one hypoglycemic event during treatment (Table 1). Among the 16 women (3.6\%) with severe hypoglycemia, two reported an inability to self-treat their symptoms. No women had symptoms of neuroglucopenia. The proportion of hypoglycemic episodes was lower $(9.1 \%)$ in women treated with insulin, but it is noteworthy that the proportion of severe hypoglycemic episodes with glyburide decreased dramatically during the course of the trial and was close to that associated with insulin (i.e., almost zero) after two years of prescribing experience (Figure 2). We found no factors associated with severe hypoglycemia, likely due to this strong learning-curve phenomenon. More precisely, there were no factors significantly associated with severe hypoglycemia episodes in the insulin group. In the glyburide group, there were only slight differences in postprandial or fasting blood glucose at randomization between women with or without a hypoglycemia episode (supplementary Tables A1 and A2). The mean dose received by the women randomized to the glyburide group was 5.7 $\mathrm{mg} /$ day and $69.8 \%$ of the women had a dosage less than $10 \mathrm{mg} /$ day. There was no 
Diabetes \& Metabolism - accepted version

significant trend in the mean dose of glyburide with time $(p=0.79)$. The mean dose of insulin received by women randomized to the insulin group was 19.6 IU/day, and $84.5 \%$ of the women were treated with a dosage of insulin less than $40 \mathrm{IU} /$ day.

Glyburide therapy failure

Compared to women who remained on glyburide treatment, women switched to insulin were significantly older and were slightly more often multiparous (mainly because they are older). There was no significant difference between the two groups in pre-pregnancy BMI or previous GDM. They had significantly poorer glycemic control at randomization before medical treatment (Table 2) either fasting or postprandial. When fasting and post-prandial glycemic control were considered together, the proportion or glyburide therapy failure was $15.8 \%$ when only fasting glycemic control was sub-optimal, $18.8 \%$ when only post-prandial glycemic control was suboptimal and $26.8 \%$ when both glycemic control were sub-optimal.

Half of the 81 women who were switched did so in the $3^{\text {rd }}$ week of glyburide treatment or before. A large majority had sub-optimal glycemic control before the switch, either fasting (61.5\%) or postprandial (82.7\%). However 8 women were switched despite optimal glycemic control, both fasting and post-prandial, so it is possible that in some cases hypoglycemia may lead to stop glyburide treatment. The proportions of hypoglycemia and severe hypoglycemia cases before the switch were $33.3 \%$ and $3.7 \%$, respectively and were of the same magnitude than those in women treated with glyburide until the end of pregnancy.

After the switch, glycemic control with insulin improved: $42.3 \%$ of women had suboptimal fasting glycemic control and $61.5 \%$ had sub-optimal postprandial glycemic control. The proportions of hypoglycemia and severe hypoglycemia cases decreased to $7.4 \%$ and $0 \%$, respectively, which were of the same magnitude as for women treated with insulin since randomization. 


\section{Discussion}

\section{Statement of principal findings}

This ancillary analysis of the INDAO trial [13] provides new information on women with GDM treated with glyburide. More than $50 \%$ of the women have optimal glycemic control with glyburide (i.e. less than $20 \%$ of their blood glucose values exceeded the targets) and an average of 0.80 of blood glucose values are within the targets. These results were similar to those with insulin. Around $40 \%$ of the women have had at least one episode of hypoglycemia, which is more than with insulin, though those hypoglycemic episodes were mostly moderate, and the rate of severe hypoglycemia with glyburide decreased during the course of the trial. Finally, glyburide treatment failed in $18 \%$ of the women who were switched to insulin, helping to improve their glycemic control.

Strengths and weaknesses in relation to other studies, discussing important differences in results

These results are in line with previous publications of randomized controlled trials and meta-analyses concluding that glyburide and insulin are equally effective in normalizing maternal glucose levels in GDM [7-12]. However, the way that glycemic control was quantified in many of these studies (mean of fasting or preprandial and postprandial blood glucose) did not always take into account glycemic profile and the frequency of glucose excursions. In our study, we used a pragmatic indicator to assess glycemic control for each woman individually (percentage of fasting and 2hour postprandial blood glucose values exceeding the targets currently recommended [3-5]). This indicator is an approximation of the "time in range" derived from continuous glucose monitoring, a method that allows total glucose exposure and variability to be quantified. However, continuous glucose monitoring is not used routinely in GDM since it has been evaluated during pregnancy mainly in women with 
pre-existing diabetes [19-22] and only one trial in women with type 1 diabetes has shown some advantages of its use in terms of glycemic control or neonatal outcomes [19].

Maternal hypoglycemia, both moderate and severe, was more frequent in the glyburide group compared to the insulin group. Glyburide as an insulin secretagogue may cause greater risk than additional insulin because stimulated endogenous insulin secretion cannot be reduced during hypoglycemia. The rate of severe maternal hypoglycemia (blood glucose $<40 \mathrm{mg} / \mathrm{dL}$ ) during glyburide treatment was close to that reported in the main trial using the same glyburide regiment [6]. However, the rate of severe hypoglycemia we observed in the insulin group was much lower than that reported by Langer et al in the first large randomized trial [6]. This could be due to our precautionary modalities of insulin titration in women with significant residual insulin secretion, in order to avoid maternal hypoglycemia. Interestingly, the rate of severe maternal hypoglycemia with glyburide treatment decreased significantly over time, which corresponded to the learning curve needed to use glyburide cautiously in order to prevent hypoglycemia: time of administration of glyburide and distribution of carbohydrates between meals and snacks could be adapted according to individual glycemic profile.

The doses of glyburide used in our study were relatively low: $5.7 \mathrm{mg} / \mathrm{day}$ on average and almost $70 \%$ of the women received less than $10 \mathrm{mg} /$ day. Other studies have also found that women treated with glyburide achieve the desired level of glycemic control during pregnancy with low glyburide dosages $(10 \mathrm{mg} / \mathrm{day}$ or less): observational studies [23-25] and a secondary analysis of a large randomized trial which found that only $6 \%$ of patients in the well-controlled group required high doses of glyburide (>10 mg/day) [26]. Therefore, it can be argued that women responding to glyburide need only small doses to achieve glycemic control. 
Like most studies, we have defined "glyburide treatment failure" as the fact that a woman treated with glyburide was switched to insulin by her supervising clinician due to sub-optimal glucose control. This is a proxy since sub-optimal glycemic control may also be observed in some women who were not switched to insulin, although it could be considered as another form of glyburide failure. It is also noteworthy that, similarly, some women not optimally controlled with insulin could be considered as "insulin treatment failure". Our finding of $18 \%$ women with glyburide failure is consistent with reports of cohort studies [24, 25, 27, 28] and a meta-analysis [7].

We found few predictors of glyburide treatment failure (maternal age and sub-optimal glycemic control before treatment) and their predictive ability is limited. This is consistent with previous studies suggesting that pretreatment glycemic values [24, $25,27,28]$, maternal age and parity [28], and early diagnosis of GDM $[27,28]$ may be associated with treatment failure. Therefore, in clinical practice, it is difficult to predict the failure and thus to select women who are likely to respond well to glyburide. However, since glyburide is usually effective at low dosages in patients who respond to it [24-26], and because sub-optimal glycemic control the week following treatment initiation is predictive of treatment failure [27], women in whom glyburide treatment will fail can be detected early in clinical practice. Moreover, since glycemic control can be markedly improved after a switch to insulin, there is no chance lost for a woman initially treated with glyburide of reaching the glycemic targets recommended during pregnancy.

Based on these results and its greater ease of use, after informing patients of the balance of risks and benefits, glyburide could be considered as an alternative treatment in women with GDM for whom the constraints of insulin therapy are too great and could lead to poor observance. 
Diabetes \& Metabolism - accepted version

Strengths and weaknesses of the study

The main strength of our study is its large size and that it is part of a randomized controlled trial, which involves rigorous monitoring of women and their treatment. Therefore, most potential glucose measurement biases were limited. Glycemic control was assessed prospectively at each visit, allowing us to quantify it accurately throughout pregnancy.

The main limitation of our study is the substantial percentage of women who were switched from glyburide to insulin. This situation was foreseen in the protocol and the percentage was expected, but it does not allow for an unbiased description of the women treated with glyburide. Our choice to maintain these women in their initial treatment group is similar to an intention-to-treat analysis. It avoids excluding women whose glycemic control is more difficult to achieve and therefore avoids overestimating glyburide results. Symmetrically, it tends to underestimate treatment results with glyburide and possible differences from insulin in glycemic control.

\section{Conclusion}

Glyburide is an effective treatment for reaching glycemic goals during pregnancy in women with GDM. However, the use of glyburide requires a clear understanding of its mechanism of action and a learning period may be necessary to reduce the rate of maternal hypoglycemia. Glyburide failure is difficult to predict, but can be detected early during the first weeks of treatment, in which case the switch to insulin rapidly improves glycemic control. These findings could be taken into account in the management of GDM. 


\section{Funding}

This study was supported by a research grant from the French Ministry of Health and was sponsored by Paris Public Hospitals (AP-HP, Assistance Publique des Hôpitaux de Paris), via its Clinical Research Department. The funders had no role in study design, data collection and analysis, decision to publish, or preparation of the manuscript.

\section{Author Contributions}

HA, MVS, JB conceived the study, analyzed and interpreted the data, drafted the first version of this article, and reviewed/edited the manuscript.

HB, MC, PD critically revised the manuscript and reviewed/edited it.

MVS and JB had full access to all the data in the study and take responsibility for the integrity of the data and the accuracy of the data analysis.

\section{Acknowledgements}

We thank David Marsh, BSc (Biophysics, First Class Honours, University of Leeds, UK) PhD (Biophysics, King's College London, UK), freelance translator and copyeditor/proofreader for language editing. He received compensation for this work.

\section{Conflict of Interest Disclosure}

The authors do not report any potential conflicts of interest.

\section{Data availability}

Data of the INDAO trial cannot be shared publicly as it contains sensitive patient information and is the property of AP-HP (Paris Public Hospitals). Consultation of the data by other interested researchers may be considered by AP-HP, subject to prior determination of the terms and conditions of such consultation and in respect of compliance with the applicable 
Diabetes \& Metabolism - accepted version

French and European regulations. Requests should be addressed to the Delegation for

Clinical Research and Innovation (DRCI) at secretariat-direction.drc@aphp.fr. 


\section{References}

[1] Durnwald C. Gestational diabetes: Linking epidemiology, excessive gestational weight gain, adverse pregnancy outcomes, and future metabolic syndrome. Semin Perinatol 2015;39(4):254-8.

[2] Mack LR, Tomich PG. Gestational Diabetes: Diagnosis, Classification, and Clinical Care. Obstet Gynecol Clin North Am 2017;44(2):207-17.

[3] Crowther CA, Hiller JE, Moss JR, McPhee AJ, Jeffries WS, Robinson JS, et al. Effect of treatment of gestational diabetes mellitus on pregnancy outcomes. $\mathrm{N}$ Engl J Med 2005;352(24):2477-86.

[4] Landon MB, Spong CY, Thom E, Carpenter MW, Ramin SM, Casey B, et al. A multicenter, randomized trial of treatment for mild gestational diabetes. $\mathrm{N}$ Engl $\mathrm{J}$ Med 2009;361(14):1339-48.

[5] American Diabetes Association. 14. Management of Diabetes in Pregnancy: Standards of Medical Care in Diabetes-2019. Diabetes Care 2019;42(Suppl 1):S165S72.

[6] Langer O, Conway DL, Berkus MD, Xenakis EM, Gonzales O. A comparison of glyburide and insulin in women with gestational diabetes mellitus. $\mathrm{N}$ Engl $\mathrm{J}$ Med 2000;343(16):1134-8.

[7] Balsells M, Garcia-Patterson A, Sola I, Roque M, Gich I, Corcoy R. Glibenclamide, metformin, and insulin for the treatment of gestational diabetes: a systematic review and meta-analysis. BMJ 2015;350:h102.

[8] Dhulkotia JS, Ola B, Fraser R, Farrell T. Oral hypoglycemic agents vs insulin in management of gestational diabetes: a systematic review and metaanalysis. Am J Obstet Gynecol 2010;203(5):457 e1-9.

[9] Jiang YF, Chen XY, Ding T, Wang XF, Zhu ZN, Su SW. Comparative efficacy and safety of OADs in management of GDM: network meta-analysis of randomized controlled trials. J Clin Endocrinol Metab 2015;100(5):2071-80.

[10] Song R, Chen L, Chen Y, Si X, Liu Y, Liu Y, et al. Comparison of glyburide and insulin in the management of gestational diabetes: A meta-analysis. PLoS One 2017;12(8):e0182488.

[11] Poolsup N, Suksomboon N, Amin M. Efficacy and safety of oral antidiabetic drugs in comparison to insulin in treating gestational diabetes mellitus: a meta-analysis. PLoS One 2014;9(10):e109985.

[12] Zeng YC, Li MJ, Chen Y, Jiang L, Wang SM, Mo XL, et al. The use of glyburide in the management of gestational diabetes mellitus: a meta-analysis. Adv Med Sci 2014;59(1):95-101.

[13] Senat MV, Affres H, Letourneau A, Coustols-Valat M, Cazaubiel M, Legardeur $H$, et al. Effect of Glyburide vs Subcutaneous Insulin on Perinatal Complications Among Women With Gestational Diabetes: A Randomized Clinical Trial. JAMA 2018;319(17):1773-80.

[14] International Association of Diabetes - Pregnancy Study Groups Consensus Panel, Metzger BE, Gabbe SG, Persson B, Buchanan TA, Catalano PA, et al. International association of diabetes and pregnancy study groups recommendations on the diagnosis and classification of hyperglycemia in pregnancy. Diabetes Care 2010;33(3):676-82.

[15] Vayssiere $\mathrm{C}$, Grandjean $\mathrm{H}$. Expert consensus on gestational diabetes mellitus. Methods and organization. Diabetes Metab 2010;36(6 Pt 2):512-4.

[16] Royston P, Sauerbrei W. Multivariable model-building. A pragmatic approach to regression analysis based on fractional polynomials for modelling continuous variables. Chichester: John Wiley \& Sons; 2008.

[17] Raudenbush SW, Bryk AS. Hierarchical Linear Models: Applications and Data Analysis Methods. 2nd ed. Thousand Oaks: SAGE Publications; 2002.

[18] StataCorp. Stata Statistical Software: Release 15. College Station (TX): StataCorp LLC; 2017.

[19] Feig DS, Donovan LE, Corcoy R, Murphy KE, Amiel SA, Hunt KF, et al. Continuous glucose monitoring in pregnant women with type 1 diabetes (CONCEPTT): a 
multicentre international randomised controlled trial. Lancet 2017;390(10110):234759.

[20] Kristensen K, Ogge LE, Sengpiel V, Kjolhede K, Dotevall A, Elfvin A, et al. Continuous glucose monitoring in pregnant women with type 1 diabetes: an observational cohort study of 186 pregnancies. Diabetologia 2019.

[21] Secher AL, Ringholm L, Andersen HU, Damm P, Mathiesen ER. The effect of realtime continuous glucose monitoring in pregnant women with diabetes: a randomized controlled trial. Diabetes Care 2013;36(7):1877-83.

[22] Voormolen DN, DeVries JH, Sanson RME, Heringa MP, de Valk HW, Kok M, et al. Continuous glucose monitoring during diabetic pregnancy (GlucoMOMS): A multicentre randomized controlled trial. Diabetes Obes Metab 2018;20(8):1894-902.

[23] Jacobson GF, Ramos GA, Ching JY, Kirby RS, Ferrara A, Field DR. Comparison of glyburide and insulin for the management of gestational diabetes in a large managed care organization. Am J Obstet Gynecol 2005;193(1):118-24.

[24] Rochon M, Rand L, Roth L, Gaddipati S. Glyburide for the management of gestational diabetes: risk factors predictive of failure and associated pregnancy outcomes. Am J Obstet Gynecol 2006;195(4):1090-4.

[25] Yogev Y, Melamed N, Chen R, Nassie D, Pardo J, Hod M. Glyburide in gestational diabetes--prediction of treatment failure. J Matern Fetal Neonatal Med 2011;24(6):842-6.

[26] Langer O, Yogev Y, Xenakis EM, Rosenn B. Insulin and glyburide therapy: dosage, severity level of gestational diabetes, and pregnancy outcome. Am J Obstet Gynecol 2005;192(1):134-9.

[27] Harper LM, Glover AV, Biggio JR, Tita A. Predicting failure of glyburide therapy in gestational diabetes. J Perinatol 2016;36(5):347-51.

[28] Kahn BF, Davies JK, Lynch AM, Reynolds RM, Barbour LA. Predictors of glyburide failure in the treatment of gestational diabetes. Obstet Gynecol 2006;107(6):1303-9. 
Table 1: Glycemic control and hypoglycemia during treatment

$$
\begin{array}{cc}
\text { Glyburide } & \text { Insulin } \\
n=448 & n=442
\end{array}
$$

\begin{tabular}{|c|c|c|c|}
\hline \multicolumn{4}{|l|}{$\begin{array}{l}\text { Mean of the proportions per woman of blood glucose } \\
\text { values within the targets during treatment * }\end{array}$} \\
\hline Mean proportion of fasting blood glucose $\leq 95 \mathrm{mg} / \mathrm{dL}$ & 0.82 & 0.80 & 0.21 \\
\hline $\begin{array}{l}\text { Mean proportion of postprandial blood glucose } \leq 12 \\
\mathrm{mg} / \mathrm{dL}\end{array}$ & 0.77 & 0.78 & 0.48 \\
\hline \multicolumn{4}{|l|}{$\begin{array}{l}\text { Proportion of women with optimal glycemic control during } \\
\text { treatment }\end{array}$} \\
\hline$\leq 20 \%$ of fasting blood glucose values $>95 \mathrm{mg} / \mathrm{dL}$ & $66.3 \%$ & $63.2 \%$ & 0.34 \\
\hline $\begin{array}{l}\leq 20 \% \text { of postprandial blood glucose values }>120 \\
\mathrm{mg} / \mathrm{dL}\end{array}$ & $50.8 \%$ & $49.3 \%$ & 0.66 \\
\hline Maternal hypoglycemia † (\%) & $41.1 \%$ & $9.1 \%$ & $<0.001$ \\
\hline Severe maternal hypoglycemia $\ddagger(\%)$ & $3.6 \%$ & $0.9 \%$ & 0.01 \\
\hline
\end{tabular}

* For each woman, we computed the number of blood glucose values within the targets in all her blood glucose assays, from randomization to delivery, divided by the total number of her blood glucose values. The mean of these proportions was calculated.

$\dagger$ at least one fasting or postprandial blood glucose measurement $<60 \mathrm{mg} / \mathrm{dL}$ during treatment $\ddagger$ at least one fasting or postprandial blood glucose measurement $<40 \mathrm{mg} / \mathrm{dL}$ during treatment 
Table 2: Failure of glyburide therapy

Failure of glyburide

$\begin{array}{cc}\text { No } & \text { Yes } \\ n=367 & n=81\end{array}$

\begin{tabular}{lccc}
\hline Age, mean, years & 32.5 & 34.3 & 0.01 \\
\hline Multiparous & $58.9 \%$ & $69.1 \%$ & 0.09 \\
\hline Pre-pregnancy BMI, mean, kg/m² & 27.3 & 28.1 & 0.27 \\
\hline Geographical origin & & $40.5 \%$ & \\
Europe & $41.1 \%$ & $30.4 \%$ & $18.5 \%$ \\
North Africa & $34.9 \%$ & $5.1 \%$ & $7.6 \%$ \\
Sub-Saharan Africa & $9.9 \%$ & $23.5 \%$ & 0.48 \\
Asia & $5.4 \%$ & & \\
Other & $8.7 \%$ & $21.1 \%$ & 0.53 \\
\hline Previous gestational diabetes & $20.0 \%$ & & \\
\hline Previous gestational diabetes treated with & & & \\
insulin (among women with previous gestational & $28.2 \%$ & & \\
diabetes) & & & \\
\hline
\end{tabular}

$\mathrm{GA}^{\mathrm{a}}$ at OGTT screening ${ }^{\mathrm{b}}$, median (IQR),

weeks $^{\text {+days }}$

Mean of the proportions per woman * of blood

glucose values within the targets at

randomization

Fasting blood glucose $\leq 95 \mathrm{mg} / \mathrm{dL}$

0.62

0.51

0.01

Postprandial blood glucose $\leq 120 \mathrm{mg} / \mathrm{dL}$

0.78

0.71

0.001

Proportion of women with optimal glycemic

control at randomization

$\leq 20 \%$ of Fasting blood glucose results $>95$

$\mathrm{mg} / \mathrm{dL}$

$38.0 \%$

$24.7 \%$

0.03

$\leq 20 \%$ of Postprandial blood $\mathrm{g}>120 \mathrm{mg} / \mathrm{dL}$

$59.4 \%$

$40.7 \%$

0.01

* For each woman, we computed the number of blood glucose values exceeding targets in all her blood glucose assays during the diet phase, between diagnosis and randomization divided by the total number of her blood glucose values.. The mean of these proportions was calculated. 
Figure 1: Glycemic control during pregnancy according to the treatment group (insulin or glyburide): curves and 95\% confidence intervals
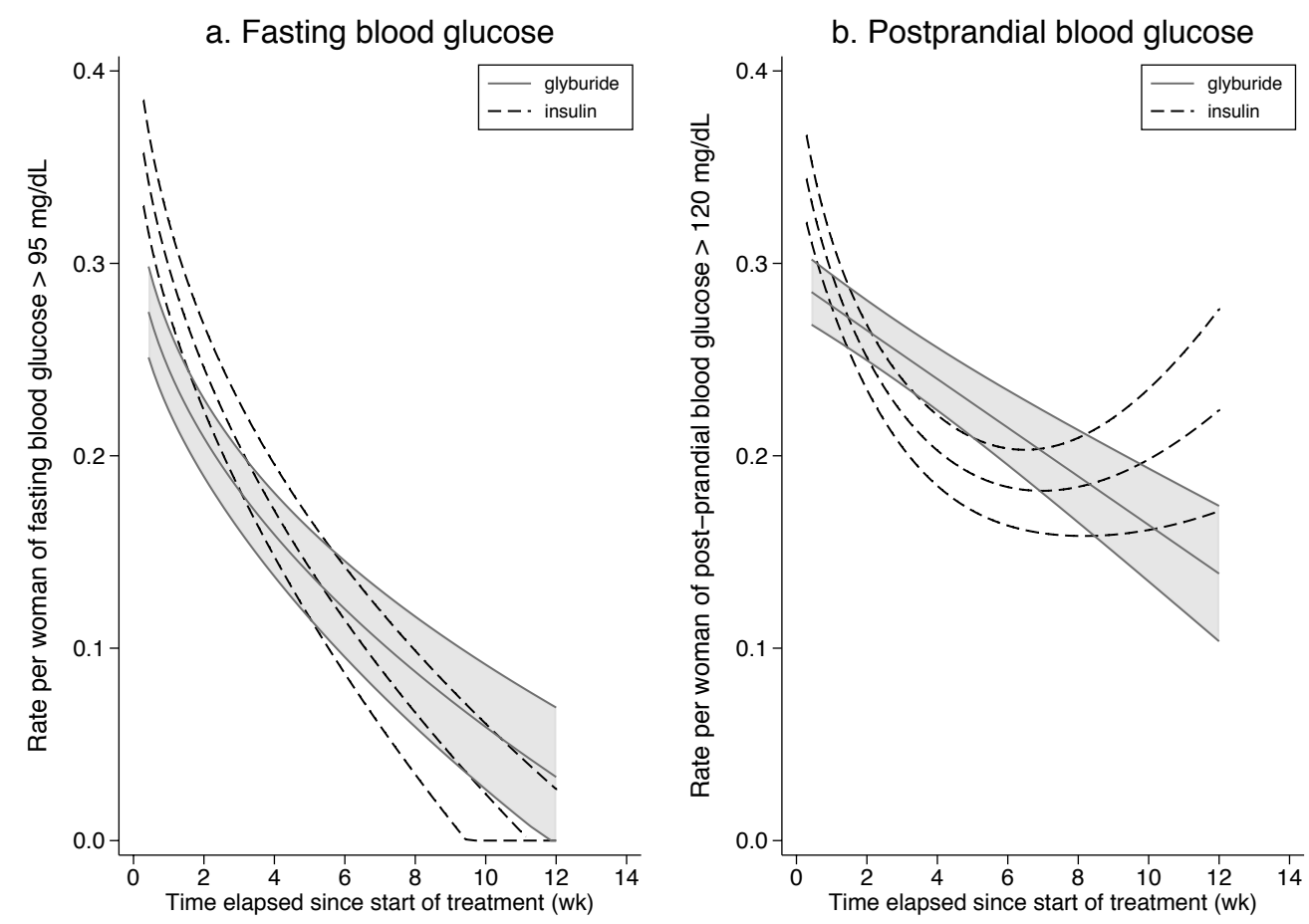

Figure 2: Rate of severe maternal hypoglycemia (blood glucose $<40 \mathrm{mg} / \mathrm{dL}$ ) during the course of the trial according to the treatment group: curves and $95 \%$ confidence intervals

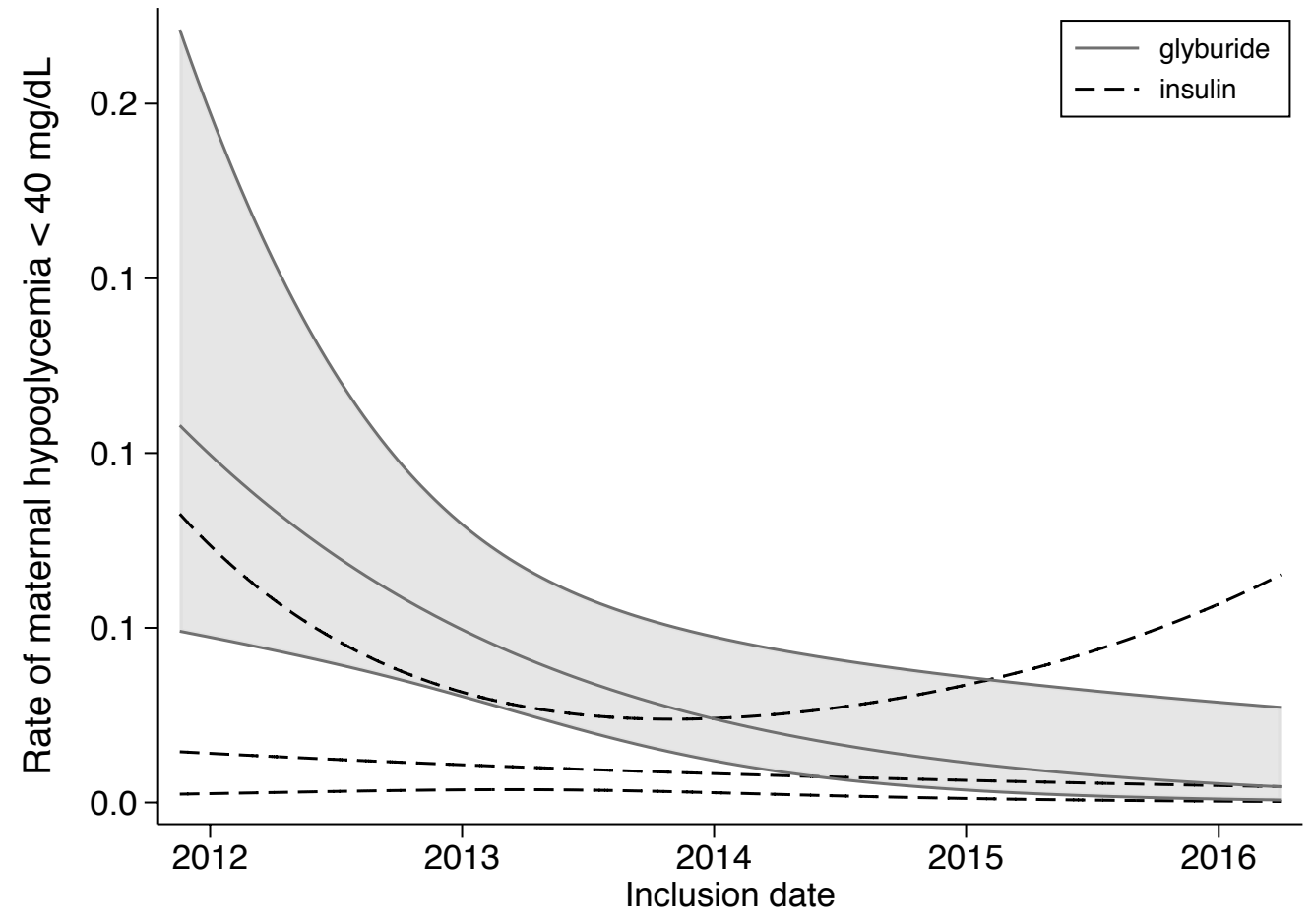




\section{Supplementary material}

Table A1. Characteristics of the women with an episode of hypoglycemia defined as blood glucose below $60 \mathrm{mg} / \mathrm{dL}$. Glyburide therapy group.

At least one hypoglycemia episode

\begin{tabular}{|c|c|c|c|}
\hline & $\begin{array}{c}\text { No } \\
(n=264)\end{array}$ & $\begin{array}{c}\text { Yes } \\
(n=184)\end{array}$ & $\mathrm{p}$ \\
\hline Age, mean (SD), years & $32.4(5.1)$ & $33.4(5.2)$ & 0.04 \\
\hline Multiparity, No (\%) & $158(59.9)$ & $114(62.9)$ & 0.65 \\
\hline Pre-pregnancy BMI, mean (SD), kg/m² & $27.8(5.7)$ & $26,9(5.3)$ & 0.10 \\
\hline $\mathrm{BMI}$ at diagnosis, mean (SD), $\mathrm{kg} / \mathrm{m}^{2}$ & $31.1(5.2)$ & $30.2(5.1)$ & 0.08 \\
\hline Geographical origin, No (\%) & & & 0.14 \\
\hline Europe & $114(44.9)$ & $64(35.6)$ & \\
\hline North Africa & $86(33.9)$ & $62(34.4)$ & \\
\hline Sub-Saharan Africa & $22(8.7)$ & $26(14.4)$ & \\
\hline Asia & $14(5.5)$ & $9(5.0)$ & \\
\hline Other & $18(7.1)$ & $19(10.6)$ & \\
\hline Previous gestational diabetes, No (\%) & $49(18.6)$ & $43(23.4)$ & 0.24 \\
\hline $\begin{array}{l}\mathrm{GA}^{\mathrm{a}} \text { at OGTT screening } \\
(\mathrm{b}, \text {, median } \\
(\mathrm{QR}) \text {, weeks }\end{array}$ & $26^{+5}\left(25^{+3}\right.$ to $\left.28^{+0}\right)$ & $26^{+3}\left(25^{+1}\right.$ to $\left.28^{+0}\right)$ & 0.58 \\
\hline $\begin{array}{l}\text { Type of abnormal blood glucose at } \\
\text { randomization, No. (\%) }\end{array}$ & & & 0.02 \\
\hline only fasting & $10(3.8)$ & $2(1.1)$ & \\
\hline only $2 \mathrm{~h}$ postprandial & $33(12.5)$ & $39(21.2)$ & \\
\hline both fasting and $2 \mathrm{~h}$ postprandial & $221(83.7)$ & $143(77.7)$ & \\
\hline \multicolumn{4}{|l|}{$\begin{array}{l}\text { Mean of the proportions per woman }{ }^{c} \\
\text { of blood glucose values within the } \\
\text { targets at randomization }\end{array}$} \\
\hline Fasting blood glucose $\leq 95 \mathrm{mg} / \mathrm{dL}$ & 0.57 & 0.64 & 0.04 \\
\hline $\begin{array}{l}\text { Postprandial blood glucose } \leq 120 \\
\mathrm{mg} / \mathrm{dL}\end{array}$ & 0.78 & 0.75 & 0.10 \\
\hline
\end{tabular}

a GA: gestational age

b OGTT: oral glucose tolerance test

${ }^{c}$ For each woman, we computed the number of blood glucose values exceeding targets in all her blood glucose assays during the diet phase, between diagnosis and randomization. The mean of these proportions was calculated. 
Table A2. Characteristics of the women with an episode of hypoglycemia defined as blood glucose below $40 \mathrm{mg} / \mathrm{dL}$. Glyburide therapy group.

At least one hypoglycemia episode

\begin{tabular}{|c|c|c|c|}
\hline & $\begin{array}{c}\text { No } \\
(n=432)\end{array}$ & $\begin{array}{c}\text { Yes } \\
(n=16)\end{array}$ & $p$ \\
\hline Age, mean (SD), years & $32.8(5.1)$ & $32.8(6.9)$ & 0.99 \\
\hline Multiparity, No (\%) & $262(60.7)$ & $10(62.5)$ & 0.82 \\
\hline Pre-pregnancy BMI, mean (SD), kg/m² & $27.5(5.6)$ & $27.5(6.1)$ & 0.98 \\
\hline $\mathrm{BMI}$ at diagnosis, mean (SD), $\mathrm{kg} / \mathrm{m}^{2}$ & $30.8(5.2)$ & $30.4(5.6)$ & 0.77 \\
\hline $\begin{array}{l}\text { Geographical origin, No (\%) } \\
\text { Europe } \\
\text { North Africa } \\
\text { Sub-Saharan Africa } \\
\text { Asia } \\
\text { Other }\end{array}$ & $\begin{array}{c}173(41.3) \\
140(33.4) \\
47(11.2) \\
23(5.5) \\
36(8.6)\end{array}$ & $\begin{array}{c}5(33.3) \\
8(53.3) \\
1(6.7) \\
0(0.0) \\
1(6.7)\end{array}$ & 0.71 \\
\hline Previous gestational diabetes, No (\%) & $86(20.0)$ & $6(7.5)$ & 0.10 \\
\hline $\begin{array}{l}\mathrm{GA}^{\mathrm{a}} \text { at OGTT screening }{ }^{\mathrm{b}}, \text { median } \\
(\mathrm{IQR}) \text {, weeks }\end{array}$ & $26^{+4}\left(25^{+2}\right.$ to $\left.28^{+0}\right)$ & $26^{+2}\left(25^{+0}\right.$ to $\left.27^{+5}\right)$ & 0.63 \\
\hline $\begin{array}{l}\text { Type of abnormal blood glucose at } \\
\text { randomization, No. (\%) }\end{array}$ & & & 1.00 \\
\hline only fasting & $12(2.8)$ & $0(0.0)$ & \\
\hline only $2 \mathrm{~h}$ postprandial & $70(16.2)$ & $2(12.5)$ & \\
\hline both fasting and $2 \mathrm{~h}$ postprandial & $350(81.0)$ & $14(67.5)$ & \\
\hline \multicolumn{4}{|l|}{$\begin{array}{l}\text { Mean of the proportions per woman }{ }^{c} \\
\text { of blood glucose values within the } \\
\text { targets at randomization }\end{array}$} \\
\hline Fasting blood glucose $\leq 95 \mathrm{mg} / \mathrm{dL}$ & 0.60 & 0.54 & 0.47 \\
\hline $\begin{array}{l}\text { Postprandial blood glucose } \leq 120 \\
\mathrm{mg} / \mathrm{dL}\end{array}$ & 0.77 & 0.69 & 0.06 \\
\hline
\end{tabular}

a GA: gestational age

b OGTT: oral glucose tolerance test

${ }^{c}$ For each woman, we computed the number of blood glucose values exceeding targets in all her blood glucose assays during the diet phase, between diagnosis and randomization. The mean of these proportions was calculated. 